\title{
Analisa Pembangkit Listrik Tenaga Uap Skala Laboratorium Dengan Bahan Bakar LPG
}

\author{
Jatmiko Edi Siswanto \\ Program Studi Teknik Mesin, Sekolah Tinggi Teknologi Nasional Jambi \\ Jl. Patimura No.100, Rawa Sari, Kota Baru, Jambi 36125 \\ Correspondence Email: jatmikoedis@mail.com
}

\begin{abstract}
Abstrak. Turbin uap merupakan suatau pengerak mula yang mengubah energi potensial uap menjadi energi kinetik dan selajutya diubah menjadi energi mekanis dalam bentuk putaran poros turbin, langsung atau dengan bantuan roda gigi reduksi, dihubungkan dengan mekanisme yang akan digerakan. Didalam penelitian untuk menganalisis kinerja turbin uap dengan bahan bakar gas LPG. Dimana dalam penelitian ini dengan menggunakan hasil uap basah untuk menggerakkan poros turbin yang mana dengan variasi tekanan (7Bar, 6Bar, 5Bar dan 4Bar). Sehingga diperoleh hasil maksimal yaitu 7 Bar diperoleh massa uap 0,09 dengan waktu 1,5 jam dengan pemanasan air 15 liter, daya uap yang dihasilkan 25,6 Watt, Daya Poros 18,01 Watt dan Daya Listrik maksimal yang dihasilkan adalah 20 Watt mendapatkan effisiensi kerja turbin 78,12\% dan mendapatkan hasil effisiensi generator $25 \%$.
\end{abstract}

Kata Kunci : Turbin Uap, Effisiensi, Generator, LPG.

\begin{abstract}
The steam turbine is an initial drive that converts the potential energy of steam into kinetic energy and is subsequently converted into mechanical energy in the form of a turbine shaft rotation, directly or with the help of a reduction gear, connected to the mechanism to be driven. In research to analyze the performance of a steam turbine using LPG gas as fuel. Where in this study using the results of wet steam to move the turbine shaft with variations in pressure (7Bar, 6Bar, 5Bar and 4Bar). So that the maximum result is 7 Bar, the steam mass obtained is 0.09 with a time of 1.5 hours by heating 15 liters of water, the steam power produced is 25.6 Watts, the shaft power is 18.01 Watts and the maximum electrical power produced is 20 Watts. the turbine work efficiency is $78.12 \%$ and the result is a generator efficiency of $25 \%$.
\end{abstract}

Keywords: Steam Turbine, Efficiency, Generator, LPG.

\section{PENDAHULUAN}

Energi listrik merupakan suatu faktor penunjang yang sanagat penting bagi perkebangan secara meyeluruh suatu bangsa. Di Indonesia, dengan semakin meningkatya kegiatan industri dan sejumlah pendudukya maka kebutuhan energi listrik mengalami peningkatan. Untuk memenuhi kebutuhan energi listrik yang semakin menikat maka telah bayak dilakukan perencanaan dan pembagunan pusat-pusat pembakit listrik seperti halnya pusat listrik tenaga uap (PLTU) di industri besar maupun industri kecil sudah bayak mengunakan listrik tenagauap. Turbin uap adalah mesin konversi energi dengan mengkonversikan energi kalor menjadi menjadi energi mekanik, dan energi mekanik menjadi energi listrik pada generator.

Boiler adalah bejana tertutup dimana panas pembakaran dialirkan ke air samapai terbentuk steam. Steam pada tekanan tertentu kemudian digunakan untuk mengalirkan panas ke suatu proses. Sistem boiler terdiri dari: sistem air umpan, sistem steam dan sistem bahan bakar. Sistem air umpan menyediakan air untuk boiler secara otomis sesuai dngan kebutuhan steam. Sistem steam mengumpulkan dan mengontrol produksi steam dalam boiler. Steam dialirkan melalaui sistem pemipaan ketitik pengguna. Sistem bahan bakar adalah semua perlatan yang digunakan untuk meyediakan bahan bakar untuk mengasilkan panas yang dibutuhkan perlatan yang diperlukan pada sistem bahan bakar tergatung pada jenis bahan bakar yang digunakan pada sistem. Air yang disuplai ke boiler untuk dirubah menjadi steam disebut air umpan.

Turbin uap merupakan suatau pengerak mula yang mengubah enrgi potensial uap mejadi energi kinetik dan selajutya diubah menjadi energi mekanis dalam bentuk putaran poros turbin, langsung atau dengan bantuan roda gigi reduksi, dihubungkan dengan mekanisme yang akan digerakan. Tergatung pada jenis mekanisme yang digunakan, turbin uap dapat digunakan pada berbagi bidang seperti pada bidang industri, untuk pembangkit tenaga listrik dan untuk transfortasi. Pada proses perubahan energi pontensial menjadi energi mekanisya yaitu dalam bentuk putaran poros dilakukan dengan berbagai cara. Salah satuya yang digunakan di PLTU.

Pada dasarya turbin uap terdiri dari dua bagian utama yaitu stator dan rotor yang merupakan komponen utama pada turbin kemudian di tambah komponen lainya yang meliputi pendukungnya seperti bantalan, kopling dan sistem bantu lainya agar kerja turbin dapat lebih baik. Sebuah turbin uap memanfaatkan energi kinetik dari fluida kerjaya yang bertambah akibat penabahan energi termal.

\section{TINJAUAN PUSTAKA}

Siklus rankine adalah siklus teoritis yang mendasari siklus kerja dari suatu pembakit daya uap. Siklus rankine berada dengan siklus-siklus udara ditinjau dari fluida kerjaya yang mengalami perubhan fase selama siklus pada saat evaporasi dan kondisi, oleh karena itu fluida 
kerja untuk siklus rankine harus merupkan uap. Siklus rankine ideal tidak melibatkan bebrapa masalah irreversibilitas internal. Irrversibilitas internal dihasilkan dari gesekan fluida, throttling, dan pencampuran, yang paling penting adalah irrversibilitas dalam turbin dan pompa dan kerugian-kerugian tekanan dalam penukarpenukar panas, pipa-pipa, bengkokan-bengkokan,dan katup-katup. Temperatur air sedikit meningkat selama proses kompersi isentropik karna ada penurunan kecil dari volume jenis air. Air masuk boiler sebagai cairan kompresi dan meninggalkan boiler uap kering. Boiler pada dasarya penukar kalor yang besar dimana sumber panas dari pembakaran gas, rektor nuklir atau sumber yang lain ditransfer secara esensial ke air pada tekanan konstan. Uap superheater masuk ke turbin yang mana uap diexpansikan secara isentropik dan menghasilkan kerja oleh putaran poros yang dihubungkan pada generator listrik. Temperatur dan tekanan uapjatuh selama proses, dimana uap masuk ke kondesor dan pada kondisi ini uap biasanya merupakan campuran cairanuap jenuh dengan kualitas tinggi.

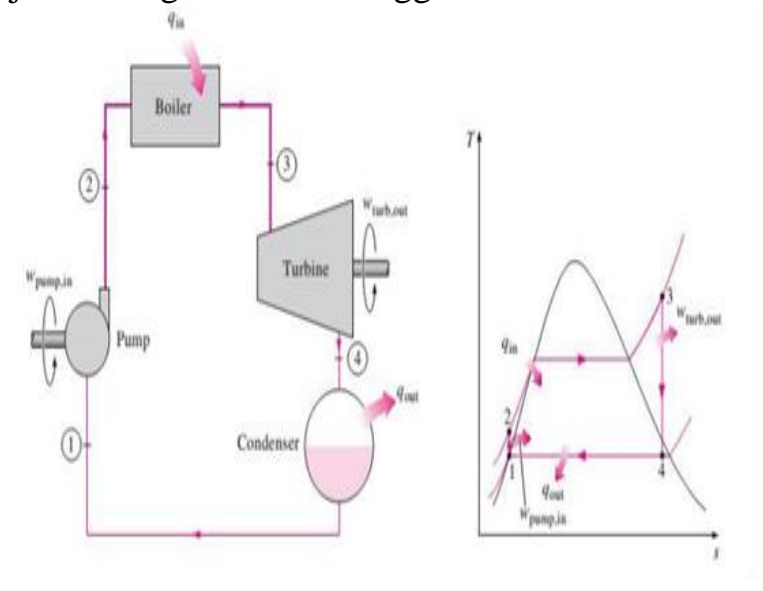

Gambar . siklus rankine dan Diagram T-s

1-2 Proses kompersi adiabatic berlangsung pada pompa. 2-3 proses pemasukan panas pada tekanan konstan terjadi boiler.

3-4 proses ekspanasi adiabitas berlangsung pada turbin uap.

4-1 proses pengeluaran panas pada tekanan konstan pada kondensor.

Uap dikondisikan pada tekanan konstan di dalam kondensor yang merupakan alat penukar kalor mengelurkan panas ke medium pendigin. Uap lajut dari katel memasuki turbin, setelah setelah melalui beberapa tingkat sudu turbin, sebagian uap diekstrasikan ke generator, sedangkan sisaya masuk ke kondensor dan dikondisikan di dalam kondensor. Selajutya air dari kondensor di pompakan ke dearator juga. Di dalam dearator, uap yang berasal dari turbin yang berupa uap basah bercampur dengan air yang berasal dari kondensor. Kemudian dari deaerator dipompakan kembali ke katel, dari katel ini air yang sudah menjadi uap kering dialirkan kembali lewat turbin. Tujuan uap diekstraksikan ke dearator adalah untuk membuang gasgas yang tidak terkondensasikan sehingga pemanasan pada ketel dapat berlangsung efektif, mencegah korosi pada ketel, dan meningkatkan efisensi siklus. Untuk mempermudah pengenelisaan siklus termodimika ini.

- Perbandingan Tekanan ( $\mathrm{p}$ )

Dalam pengambilan perbandingan tekanan pada sistem orifice, Flange Tap lokasi tekanan berada pada flange, 1 inchi upstream dan 1 inchi down stream, diukur dari permukaan upstream orifice. Pada penggunaanya ada beberapa modifikasi proses sehingga didapatkan efisiensi thermal total yang lebih tinggi. Persamaan yang digunakan pada penelitian dalam pengunaan orifice sebagai berikut:

$\Delta \mathrm{P}=\mathrm{P} \_1-\mathrm{P} \_2$

Dimana:

$$
\begin{aligned}
& \Delta \mathrm{P}=\text { Perbandingan tekanan }(\mathrm{Psi}) \\
& \mathrm{P} \_1=\text { Tekanan masuk orifice }(\mathrm{Psi}) \\
& \mathrm{P} \_2=\text { Tekanan keluar orifice (Psi) }
\end{aligned}
$$

Laju aliran masa(m) pada penelitian ini sangat penting hal ini dikarenakan berfungsi sebagai nilai menghitung nilai thermal, berikut dengan menggunakan persamaan:

$$
\begin{gathered}
(\mathrm{m}=(\mathrm{A} \sqrt{ }(2 . \Delta \mathrm{p} . \rho)) / \sqrt{ }(1-\llbracket(\mathrm{d} / \mathrm{D}) \rrbracket \wedge 4))^{\circ} \\
\text { Dimana: } \\
\mathrm{m}^{\cdot}=\text { Laju aliran massa }(\mathrm{kg} / \mathrm{s}) \\
\mathrm{A}=\text { Luas penampang orifice }(\mathrm{m} 2) \\
\rho=\text { massa jenis fluida }(\mathrm{kg} / \mathrm{m} 3) \\
\mathrm{d}=\text { diameter pipa dalam orifice }(\mathrm{m}) \\
\mathrm{D}=\text { diameter pipa uar orifice }(\mathrm{m})
\end{gathered}
$$

Torsi $(\tau)$

Neraca pegas dan dinamometer adalah salah satu alat pengukur dari torsi yang mana dengan satuan (N.m) dengan alat ini dapat mengukur putaran dari mesin dan torsi, sehingga saat mesin atau poros yang berputar maka daya atau tenaganya dapat dihitung dengan persamaan sebagai berikut:

$\tau=(\mathrm{S}-\mathrm{W}) \times \mathrm{g}$ x $\mathrm{r}$

Dimana:

$$
\begin{aligned}
& \tau=\text { Torsi }(\mathrm{N} . \mathrm{m}) \\
& \mathrm{S}=\text { pembebanan }(\mathrm{kg}) \\
& \mathrm{W}=\text { pembebanan awal }(\mathrm{kg}) \\
& \mathrm{g}=\text { gravitasi }(\mathrm{m} / \mathrm{s} 2) \\
& \mathrm{r}=\text { jari-jari }(\mathrm{m} 2)
\end{aligned}
$$

Daya Input

$$
\mathrm{Pin}=\mathrm{m}^{\cdot}(\mathrm{h} 1-\mathrm{h} 2)
$$

Dimana:

$$
\begin{array}{ll}
\text { Qin } & =\text { Daya Input (watt) } \\
\mathrm{m}^{\circ} & =\text { Laju aliran massa }(\mathrm{kg} / \mathrm{s}) \\
\text { Tin } & =\text { Enthalpy keluar boiler }(\mathrm{kJ} / \mathrm{kg}) \\
\text { Tout } & =\text { Enthalpy masuk boiler }(\mathrm{kJ} / \mathrm{kg})
\end{array}
$$

Daya Output (Watt)

Daya output yang keluar dari turbin dapat dilihat dengan persamaan sebagai berikut: 


$$
\begin{aligned}
& \text { P_out }=(\tau(.2 \times \pi \times \mathrm{n})) / 9550 \\
& \text { P_out }=\text { Daya output (Watt) } \\
& \tau \quad=\text { Torsi }(\text { N.m }) \\
& \mathrm{n}=\text { Putaran turbin }(\mathrm{rpm})
\end{aligned}
$$

Dimana:

Daya Pembebanan (Watt)

$$
\text { W_t }=\text { V.I }
$$

Dimana: $\mathrm{Wt}=$ Daya turbin (Watt)

$\mathrm{V}=$ Tegangan output dinamo (Volt)

$\mathrm{I}=$ Arus output (A)

Efisiensi Generator

$\eta$ generator $=($ Daya Pembebanan $) /($ Daya Generator $)$ x 100\% (Joko Purnomo:2018)

\section{Dimana:} keluar(Watt)

$\eta$ generator $=$ Efisiensi Generator $(\%)$

Daya Pembebanan = Hasil dari daya yang

(Watt)

Daya Generator $=$ Daya spesifikasi generator

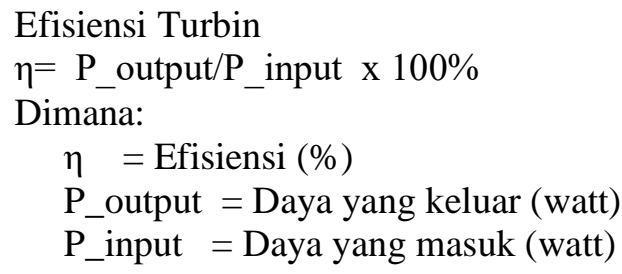

\section{METODOLOGI}

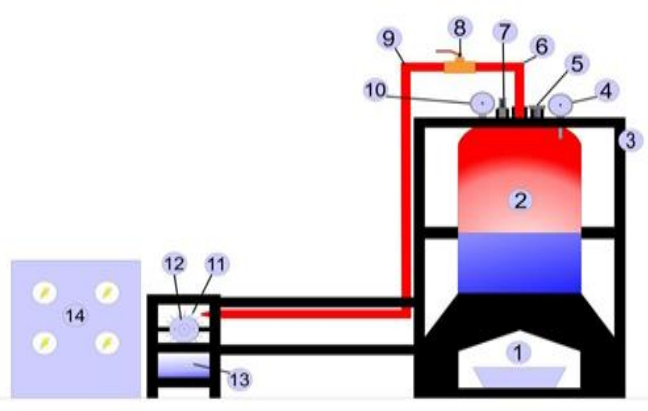

Gambar. Skema Pembangkit Listrik Tenaga Uap

Keterangan

1. Bahan Bakar 8. Valve jalur uap

2. Boiler

9. Pipa Uap

3. Rangka

10. Pengukur Air

4. Pressur Gauge

11. Turbin Ua

5. Air masuk

12. Generator

6. Pressure Gauge 13. Uap Basah

7. Jalur buang tekanan

Tabel 2. Spesifikasi Turbin Uap

Nama Spesifikasi

Turbin Uap Mini Turbin

Jumlah Sudu 11 pcs

Tekanan Masuk Max. 7 Bar

Tekanan Masuk Min. 2 Bar

Berat

$0,8 \mathrm{~kg}$

Diameter Luar

$10 \mathrm{~cm}$
Pitch $\quad 1,1 \mathrm{~cm}$

Tabel. Spesifikasi Generator

Nama Spesifikasi

Tipe 775-0-36 V

Daya Generator 80 Watt

Kecepatan Putaran 900

Tiper Arus DC

Persiapan alat penelitian

1. Pengecekan alat dan pengujian selama 60 detik.

2. Menyalakan gas lpg pada tungku.

3. Tunggu sampai tekanan uap mencapai $(4,5$ dan

6)bar dan Catat temperatur.

4. Buka valve di nomor 8 .

5. Tunggu stabilnya putaran turbin.

6. Catat putran turbin dengan alat tachometer dan catat dalam tabel.

7. Catat voltace dan harus listrik pada generator.

8. Selesai pengujian dengan tekanan $3 \mathrm{~kg}$ dan tutup valve

9. Lanjutkan dengan pengujian dengan tekanan selanjutya dengan mengulangi langkah 1-9.

\section{HASIL DAN PEMBAHASAN}

Hasil pengambilan data pengujian pada penelitian turbin uap skala laboratorium yang dilakukan pengujian di Laboratorium Teknik Mesin STITEKNAS Jambi, adapun pengujian yang dilakukan pada analisa kinerja turbin uap dengan

\begin{tabular}{|c|c|c|c|c|c|}
\hline \multirow[t]{2}{*}{\begin{tabular}{|l|} 
Tekanan \\
\end{tabular}} & \multirow{2}{*}{$\begin{array}{l}\text { Temperatur } \\
\text { Boiler }\left({ }^{\circ} \mathrm{C}\right)\end{array}$} & \multicolumn{2}{|c|}{ Berat Bahan } & \multirow{2}{*}{$\begin{array}{l}\text { Waktu Bahan Bakar } \\
\text { (Jam : Menit) }\end{array}$} & \multirow{2}{*}{$\begin{array}{c}\text { Temperatur } \\
\text { Ruang Bakar } \\
\left({ }^{\circ} \mathrm{C}\right)\end{array}$} \\
\hline & & $\begin{array}{l}\text { Awal } \\
(\mathrm{kg})\end{array}$ & $\begin{array}{c}\text { Akhir } \\
(\mathrm{kg})\end{array}$ & & \\
\hline 4 & 142 & 7,435 & 6,790 & $1: 00$ & 1022 \\
\hline 5 & 148 & 6,790 & 6,750 & $1: 15$ & 1022 \\
\hline 6 & 157 & 6,750 & 6,670 & $1: 32$ & 1022 \\
\hline 7 & 164 & 6,790 & 6,635 & $1: 50$ & 1022 \\
\hline
\end{tabular}
menggunakan bahan bakar LPG (Liquefied Petroleum Gas) dengan perbandingan setiap tekanan uap yang keluar yaitu (4 Bar, 5 Bar, 6 Bar dan 7 Bar). Tabel. Data Pengamatan Bahan Bakar

Tabel. Data Hasil Pengujian
\begin{tabular}{|c|c|c|c|c|c|c|c|}
\hline Tekanan & $\begin{array}{c}\text { P(masuk) } \\
(\text { Bar) }\end{array}$ & $\begin{array}{c}\mathrm{T} \text { (Keluar) } \\
\left({ }^{(} \mathrm{C}\right)\end{array}$ & $\begin{array}{c}\text { Beban } \\
(\mathrm{kg})\end{array}$ & $\begin{array}{c}\text { RPM } \\
\text { Voltase } \\
(\mathrm{V})\end{array}$ & $\begin{array}{c}\text { Arus } \\
\text { (Ampere) }\end{array}$ & $\begin{array}{c}\text { Waktu } \\
(\mathrm{s})\end{array}$ \\
\hline 7 & 6,8 & 94 & 4 & 940 & 20 & 1 & 120 \\
\hline 6 & 5,8 & 81 & 3,5 & 947 & 17 & 1 & 120 \\
\hline 5 & 4,8 & 78 & 2,8 & 1035 & 15 & 1 & 120 \\
\hline 4 & 3,8 & 72 & 2,5 & 1085 & 14 & 1 & 120 \\
\hline
\end{tabular}

Pengolahan Data Pengujian

Daya Uap (Watt)

Daya uap adalah energi yang dihasilkan oleh proses pemanasan pada tabung boiler yang mana hingga mencapai tekanan yang diinginkan dalam penelitian ini tekanan yang diuji adalah (7Bar, 6 Bar, 5 Bar dan 4 Bar) sehingga untuk mengetahui daya uap tersebut harus menentukan nilai enthalphy, volume spesifik, density tersebut berikut data yang diperoleh dari tabel A-3 properties of saturated water (Liquid-Vapor). 
Tabel. Nilai Enthalphy, Volume Spesifik, Suhu Temperatur terhadap Tekanan masuk Turbin

\begin{tabular}{|c|c|c|c|c|c|}
\hline $\begin{array}{c}\text { Tekanan } \\
\text { Awal } \\
(\text { Bar })\end{array}$ & $\begin{array}{c}\text { Tekanan } \\
\text { Masuk } \\
(\text { Bar })\end{array}$ & $\begin{array}{c}\text { Suhu } \\
\left({ }^{\circ} \mathrm{C}\right)\end{array}$ & $\begin{array}{c}\text { (Volume } \\
\text { Spesifik) } \\
\left(\mathrm{m}^{3} / \mathrm{kg}\right)\end{array}$ & $\begin{array}{c}\text { Density } \\
\left(\mathrm{kg} / \mathrm{m}^{3}\right)\end{array}$ & $\begin{array}{c}\text { Enthalpy } \\
(\mathrm{kJ} / \mathrm{kg})\end{array}$ \\
\hline 7 & 6,8 & 164 & 0.289 & 3,464 & 2086,30 \\
\hline 6 & 5,8 & 157 & 0.371 & 2,69 & 2090,74 \\
\hline 5 & 4,8 & 148 & 0.419 & 2,38 & 2113,38 \\
\hline 4 & 3,8 & 142 & 0.487 & 2,05 & 2139.52 \\
\hline
\end{tabular}

Tabel. Nilai Enthalphy, Volume Spesifik, Density dan Tekanan terhadapTemperatur Keluar Turbin

\begin{tabular}{|c|c|c|c|c|c|c|}
\hline $\begin{array}{c}\text { Tekanan } \\
\text { Awal } \\
(\text { Bar })\end{array}$ & $\begin{array}{c}\text { Suhu } \\
\text { Keluar } \\
\left({ }^{\circ} \mathrm{C}\right)\end{array}$ & $\begin{array}{c}\text { Tekanan } \\
(\text { Bar })\end{array}$ & $\begin{array}{c}\mathrm{CP} \\
\left(\mathrm{kJ} / \mathrm{kg} .{ }^{\circ} \mathrm{K}\right)\end{array}$ & $\begin{array}{c}(\text { Volume } \\
\text { Spesifik }) \\
\left(\mathrm{m}^{3} / \mathrm{kg}\right)\end{array}$ & $\begin{array}{c}\text { Density } \\
\left(\mathrm{kg} / \mathrm{m}^{3}\right)\end{array}$ & $\begin{array}{c}\text { Enthalpy } \\
(\mathrm{kJ} / \mathrm{kg})\end{array}$ \\
\hline 7 & 94 & 0,82 & 4,199 & 2,053 & 0,48 & 2272,42 \\
\hline 6 & 81 & 0,49 & 4,192 & 3,286 & 0,30 & 2306,78 \\
\hline 5 & 78 & 0,44 & 4,187 & 3,699 & 0,27 & 2313,86 \\
\hline 4 & 72 & 0,34 & 4,182 & 4,700 & 0,21 & 2331,03 \\
\hline
\end{tabular}

Menghitung laju aliran udara $(\mathrm{kg} / \mathrm{s})$

Diketahui bahwa diameter dari pipa nozle yang digunakan dalam penelitian adalah

$0,0025 \mathrm{~m}$

- Menghitung luas penampang

$\mathrm{A}=\pi \mathrm{r}^{\wedge} 2$

$\mathrm{A}=\pi \rrbracket(0,00125 \mathrm{~m}) \rrbracket \wedge 2$

$\mathrm{A}=0,000049 \mathrm{~m}^{\wedge} 2$

Dimana dalam mengetahui laju aliran massa sendiri diketahui diameter masuk nozzle yaitu $0,161 \mathrm{~m}$ dan diameter nozel 0,0025 $\mathrm{m}$ serta perbedaan tekanan pada proses masuk turbin dan keluar turbin sebagai beri.

- Laju aliran masa uap $(\mathrm{kg} / \mathrm{s})$

$\mathrm{m}=\left(0,02.0,0000049 \mathrm{~m} \sqrt{ }\left(2 \times 612000\left(\mathrm{~kg} /\left(\mathrm{m} \cdot \mathrm{s}^{\wedge} 2\right.\right.\right.\right.$

)$\left.\left.) .\left(0,58 \mathrm{~kg} / \mathrm{m}^{\wedge} 3\right)\right)\right) / \sqrt{ }\left(1-((0,0025 \mathrm{~m}) /(0,161 \mathrm{~m}))^{\wedge} 4\right)$

$\mathrm{m}=0,00076 \mathrm{~kg} / \mathrm{s}$

Setelah mendapatkan nilai dari laju aliran massa uap maka akan diperoleh

nilai dari masa uap, dalam penelitian ini dilakukan dengan waktu yang $120 \mathrm{~s}$.

$\mathrm{m}=\mathrm{m} \times \mathrm{s}$

$\mathrm{m}=0,00075 \mathrm{~kg} / \mathrm{s} \times 120 \mathrm{~s}$

$\mathrm{m}=0,09 \mathrm{~kg}$

Setelah mendapatkan nilai dari laju aliran massa uap maka akan diperoleh nilai dari masa uap, dalam penelitian ini dilakukan dengan waktu yang $120 \mathrm{~s}$.

$$
\begin{aligned}
& Q=0,09 \mathrm{~kg} \times 4,199 \frac{\mathrm{kJ}}{\mathrm{kg}^{\circ} \mathrm{K}} \times 342,93^{\circ} \mathrm{K} \\
& Q=138,25 \mathrm{~kJ}
\end{aligned}
$$

Dari data diatas maka diperoleh nilai Daya Uap yang dihasilkan oleh boiler terhadap turbin dengan variasi setiap tekanan yang dicapai pada waktu pemanasan yang berbeda untuk tekanan 7 Bar pada tabel 7 diperoleh waktu 1:50 jam.

$$
\begin{aligned}
& \text { Pin }=\frac{138,25 \mathrm{~kJ}}{1,50 \mathrm{Jam}} \\
& \text { Pin }=\frac{138960 \mathrm{~J}}{(1,50 \times 3600 \mathrm{~s})} \\
& \text { Pin }=25,60 \frac{\mathrm{J}}{\mathrm{s}} \\
& \text { Pin }=25,60 \mathrm{Watt}
\end{aligned}
$$

Menghitung Torsi (N.m)

Diketahui pada tekanan 7 Bar maka diperoleh massa $7 \mathrm{~kg}$ dengan jari jari diameter $0,005 \mathrm{~m}$ dengan putaran poros yaitu $940 \mathrm{rpm}$.

$$
\begin{aligned}
& \tau=\left(4 \mathrm{~kg} \times 9,81 \frac{\mathrm{m}}{\mathrm{s}^{2}}\right) \cdot 0,005 \mathrm{~m} \\
& \tau=0,183 \mathrm{~N} \cdot \mathrm{m}
\end{aligned}
$$

\section{Oleh karena itu diperoleh nilai torsi yaitu 0,183 N.m}

$$
\begin{aligned}
& P_{\text {out }}=\frac{0,183 \mathrm{~N} \cdot \mathrm{m} \times(2 \pi \cdot 1045 \mathrm{rpm})}{60} \\
& P_{\text {out }}=18,01 \mathrm{Watt}
\end{aligned}
$$

Oleh karena itu diperoleh nilai torsi yaitu 0,183 N.m

$$
\begin{aligned}
& P_{\text {out }}=\frac{0,183 \mathrm{~N} \cdot \mathrm{m} \times(2 \pi \cdot 1045 \mathrm{rpm})}{60} \\
& P_{\text {out }}=18,01 \mathrm{Watt}
\end{aligned}
$$

Diperoleh daya lampu (Daya Poros) yaitu 18,01 Watt pada kondisi 7 Bar. Menghitung Daya Turbin (Watt) Diketahui bahwa nilai voltase 20 volt serta nilai arus 1 ampere dengan pengujian 7 Bar.

\section{Menghitung Effisiensi Generator (\%)}

Dari data yang dikeluarkan turbin maka diperoleh hasil 20 Watt sedangkan untuk daya speak generator yaitu 80 Watt maka dari itu diperoleh nilai effisensi generator.

$$
\begin{aligned}
& \eta_{\text {generator }}=\frac{20 \text { Watt }}{80 \text { Watt }} \times 100 \% \\
& \eta_{\text {generator }}=25 \%
\end{aligned}
$$

Diperoleh bahwa effisensi generator terhadap daya yang dihasilkan adalah sebesar $25 \%$ dengan daya yang dihasilkan 20 Watt.

Menghitung Efisiensi Turbin (\%) 


$$
\begin{aligned}
\eta_{\text {turbin }} & =\frac{P_{\text {out }}}{P_{\text {in }}} \times 100 \% \\
\eta_{\text {turbin }} & =\frac{20 \text { Watt }}{25,60 \text { Watt }} \times 100 \% \\
\eta_{\text {turbin }} & =78,12 \%
\end{aligned}
$$

Jadi, dapat diketahui bahwa effisensi turbin uap skala laboratorium dengan tekanan 7 bar menghasilkan 78,12\%.

Analisa Data

Dari data perolehan diatas pada kinerja turbin uap skala laboratorium dengan kapasitas 80 Watt menggunakan bahan bakar LPG dapat dianalisa dengan hasil pada tabel dibawah ini.

Tabel. Data Hasil Perhitungan Turbin Uap 80 Watt

Tabel. Data Hasil Perhitungan Turbin Uap 80 Watt
\begin{tabular}{|c|c|c|c|c|c|c|c|c|c|}
\hline $\begin{array}{c}\text { Tekanan } \\
\text { Awal } \\
(\text { Bar })\end{array}$ & $\begin{array}{c}\text { Tekanan } \\
\text { Masuk } \\
(\text { Bar })\end{array}$ & $\begin{array}{c}\text { Suhu } \\
\text { Keluar } \\
\left({ }^{\circ} \mathrm{C}\right)\end{array}$ & $\begin{array}{c}\text { Massa } \\
\text { Uap } \\
(\mathrm{kg})\end{array}$ & $\begin{array}{c}\text { Daya } \\
\text { Turbin } \\
(\text { Watt })\end{array}$ & $\begin{array}{c}\text { Daya } \\
\text { Uap } \\
(\text { Watt) }\end{array}$ & $\begin{array}{c}\text { Efisiensi } \\
\text { Turbin } \\
(\%)\end{array}$ & $\begin{array}{c}\text { Daya } \\
\text { Listrik } \\
(\text { Watt) }\end{array}$ & $\begin{array}{c}\text { Daya } \\
\text { Generator } \\
(\text { Watt) }\end{array}$ & $\begin{array}{r}\text { Ef } \\
\text { Ge: }\end{array}$ \\
\hline 7 & 6,8 & 94 & 0,09 & 20 & 25,60 & 78,12 & 18,01 & 80 & \\
\hline 6 & 5,3 & 81 & 0,07 & 17 & 22,15 & 76,76 & 16,95 & 80 & ${ }^{2}$ \\
\hline 5 & 4,5 & 78 & 0,06 & 15 & 21,78 & 68,86 & 14,84 & 80 & 1 \\
\hline 4 & 3,8 & 72 & 0,05 & 14 & 21,03 & 66,56 & 13,86 & 80 & \\
\hline & & & & & & & & & \\
\hline
\end{tabular}

Dari data tersebut diatsas dapat digambarkan dalam bentuk grafik dibawah;
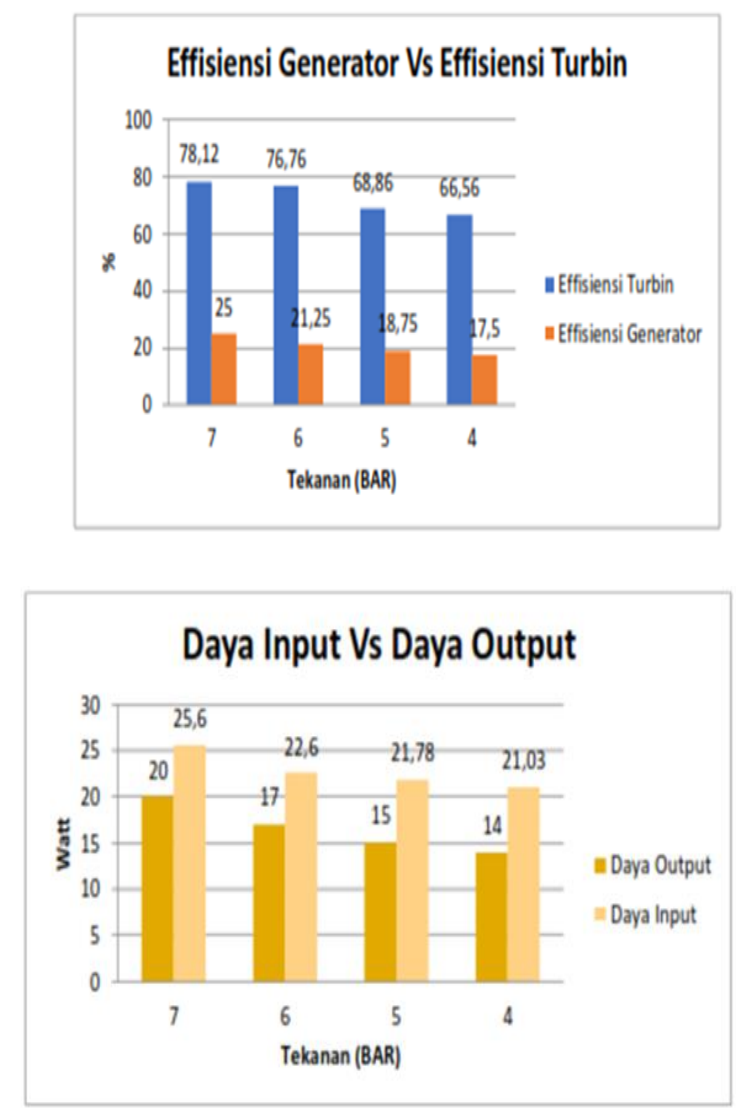

\section{KESIMPULAN}

Dari hasil penelitian yang dilakukan pada proses uji pada turbin uap skala laboratorium bahan bakar LPG, maka dapat disimpulkan sebagai berikut:
- Daya listrik yang dihasilkan oleh generator dengan proses kerja turbin uap adalah pada tekanan 4 bar (14 Watt), 5 Bar (15 Watt), (6 Bar (17 Watt) dan 7 Bar (20 Watt).

- Effisiensi dari generator dan turbin uap yang mana setiap tekanan mengalami kenaikan 4 Bar $(17,5 \% / 66,56 \%)$, 5.Bar $(18,75 \% /$ $68,86 \%), 6$ Bar $(21,25 \% / 76,76 \%)$ dan 7 Bar $(25 \% / 78,12 \%)$.

\section{DAFTAR PUSTAKA}

1. Asy'ari Daryus, 2012, Termodinamika Teknik Volume 1, Universitas Pesada

Jakarta

2. Erna Rahyu Eko Wiriani, 2019, Analisa Pengaruh Beban Listrik Terhadap Efisensi Termal PLTU Payo Selincah Jambi, Sekolah Tinggi Teknologi Nasional Jambi.

3. Joko Purnomo, 2018, Analisa Pengaruh Load Capacity Pembangkit Listrik Tenaga Uap Tanjung Awar-Awar 350 MW Terhadap Efisiensi Turbin Generator QFSN-350-2 Unit 1. JTPM. Volume 07 No. 02.

4. Nurhani Amin, 2012, Sistem Proteksi Generator Turbin Uap, Universitas Tadulako, Palu. Jurnal Majalah Ilmiah Mektek.

5. Riyki Apriandi, Awqli Mursadin, 2016, Analisis Kinerja Turbin Uap Berdasarkan Performance Test PLTU PT. Indocement P-12 Tarjun, Fakultas Teknik Mesin Universitas Lambung Mangkurat. Jurnal SJME Kinematika Vol. 1, Juni PP.37-46.

6. Sunyoto, dkk, 2008, Teknik Mesin Industri Jilid, Direktorat Pembinaan Sekolah 